\title{
Realization the Marketing Approach in the Management of the Region
}

\section{Morozova GA*}

Professor of Nizhny Novgorod Institute of Management, Russian Presidential Academy of National Economy, Russia

*Corresponding author: Morozova GA, Professor of Nizhny Novgorod Institute of Management, Russian Presidential Academy of National Economy, Russia, Tel: (831)412-21-52; E-mail: k-market@vvpaa.vvags.ru

Received date: November 13, 2014; Accepted date: December 11, 2014; Published date: December 21, 2014

Copyright: (c) 2015 Morozova GA. This is an open-access article distributed under the terms of the Creative Commons Attribution License, which permits unrestricted use, distribution, and reproduction in any medium, provided the original author and source are credited.

\begin{abstract}
Current methods of socio-economic control region requires new approaches. There is a distinction between the concept of governance in past periods and in periods associated with the unstable development of the crisis. Therefore, marketing management should combine and integrate all kinds of management activities that are based on identifying and addressing the needs and interests of the society as a whole and individual social strata and groups, to stimulate useful new society needs and interests.
\end{abstract}

The article discusses the use of the marketing approach to managing the region.

Keywords Government programs; Government marketing; Marketing; Marketing contributes; Information exchange; Government programs; State marketing; information exchange needs of the population; The need for professional recognition; The need for housing needs in education and health; Marketing management approach

\section{Introduction}

In modern conditions is actual construction of the new concept of governance in the region to effectively reform the economy and socialmarket orientation, adequate world trends.

World experience of developed countries shows a postindustrial society that determination, anticipating and satisfying the needs of society and the individual is a current trend of development. Manage the system in the region is necessary to determine, based on their own real opportunities, priorities in the activities for entering the boundaries of stability followed by the rise of socio-economic level. Modern methods of socio-economic management of the region require new approaches [1]. There is a distinction between the concept of governance in past periods and in periods associated with the unstable development of the crisis. Therefore, marketing management should combine and integrate all kinds of management activities that are based on identifying and addressing the needs and interests of the society as a whole and individual social strata and groups, to stimulate useful new society needs and interests. Certain social groups and strata of the population must see that the action of governance structures lead to complex effects to meet their needs, demands and needs [2]. These priorities, as studies show, are human and political marketing, marketing, housing, marketing education and health services. The effectiveness of the control is determined, above all, justify the use of modern approaches. In the conditions of market relations and market infrastructure priority appears marketing approach, which provides an orientation controlling subsystem in solving social and economic problems of the region on the consumer [3]. Use marketing approach leads to higher quality of the object in accordance with the needs of the consumer, saving resources for consumers by improving the quality and conserve resources in the production of services.
The aim of the article is to analyze, synthesize existing scientific approaches to management and offer greater use of public and municipal management of the marketing approach.

The methodology is based on the work of formation and use of the system of market relations and mechanisms in public and municipal administration in accordance with the priority needs of the population in the professional recognition, political allegiances, education and health services [4].

It is necessary to evaluate the types of regional policy, the boundaries and the consequences of their application, intergovernmental relations federal center and the regions. For this, we propose the following method, which uses, for example, a list of socio-economic indicators:

- The average cash income per worker.

- The unemployment rate.

- The crime rate per 10 thousand people.

- Arrears on payments to local and regional budgets.

- The index of the physical volume.

- Fiscal capacity.

- Subsidized local budget.

- Arrears of wages.

Figure 1 shows a diagram of the study.

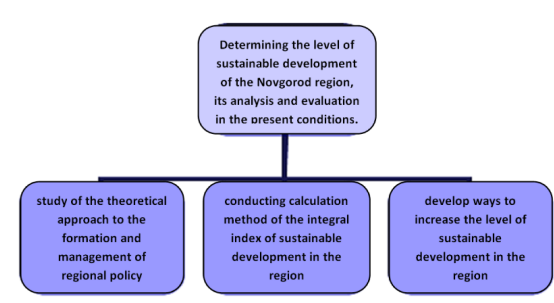

Figure 1: Scheme of calculation of the integral index of sustainable development. 
The calculation is performed in the following stages:

Step 1: Calculation of the deflection of the indicator from its boundary (critical) value.

Step 2: Calculation of the index of sustainable development indicator.

Step 3: Calculation of the integral index of sustainable development and the establishment of district seats on the scale factor of sustainable development.

Completed stages allowed graphically represent factorial scale sustainable development Diveyevsky District (Figure 2).

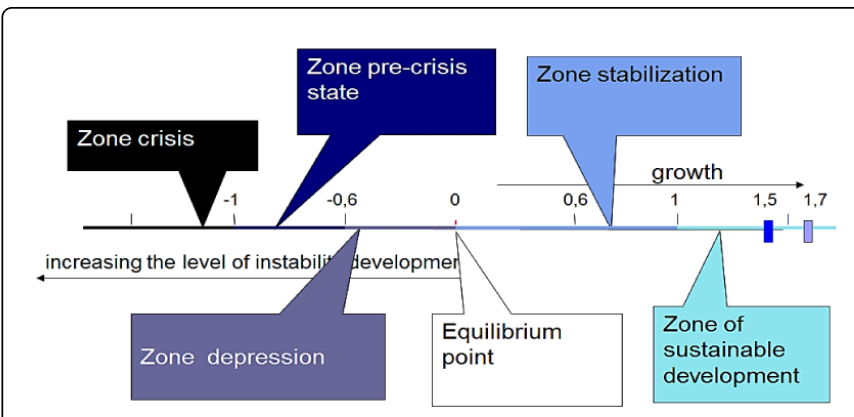

Figure 2: Factorial scale sustainable development Diveyevsky District of Nizhny Novgorod Region.

Studies show that, for example, Diveyevsky District of Nizhny Novgorod region can be recognized in the period in the territory of sustainable development (Figure 3).

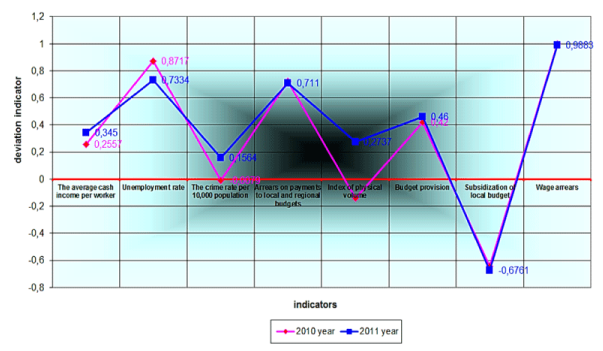

Figure 3: Comparison of deviations indicators Diveyevsky District for 2010-2011.

The proposed method allows the calculation of the integral index for each municipality the Nizhny Novgorod region and make their comparison (Figure 4).

On the basis of selected indicators from research and the dynamics of their development can draw conclusions about satisfying certain or immediate needs of the population in each municipality.

In developing the strategy for the development of each municipality in the region, should be considered priority needs residents of the territory.

In line with the developed concept proposed complex technologies and tools of marketing research and action, defines the conditions of their application, which allows meaningful reform the management of the region today. In this regard, the system needs major changes are used in the analysis of statistical indicators, they should reflect the new market innovation processes in the region and build on the transition from the solid to the reporting of sample surveys on the basis of the marketing approach.

Using models of marketing in the industrial field allows you to select as the main directions of reforming the economy in the regions of Russia are as follows:

- Formation of a post-industrial system of market relations and mechanisms of the active role of the state and municipal structures.

- The rational combination of the industrial structure and industrial policy in accordance with the structure of society and the needs of the individual.

- The orientation of the economy to meet social needs above all, the creation of mechanisms to combine economic efficiency and social justice, which will allow more rapid exit from the crisis.

- The transfer of many important powers federated entities and local governments, which are directly engaged the service of priority needs of the population: in housing, education, health care, professional recognition in the political allegiances.

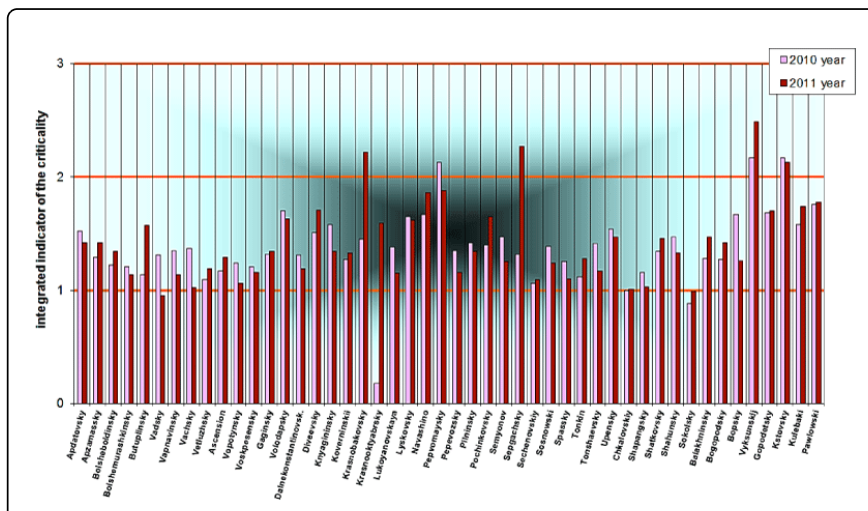

Figure 4: Dynamics of the integral index of sustainable development of the Nizhny Novgorod Region in 2010-2011.

The need for the application of marketing in the priority areas of non-industrial sphere, which is engaged in the regulation of state and local governments and governance related to the following factors:

- Increased dissatisfaction of citizens of the region the quality of work of state institutions, unable to fulfill their direct duties to service the needs of the population.

- Reducing funding government programs and services for the budget deficit.

- Increased differentiation of demand in the market of goods and services.

- Changes in the social structure of society and the emergence of new social groups and layers having their own specific interests and needs.

- The traditional bureaucratic apparatus of power that places often their corporate goals above the interests of society.

State and municipal authorities and management constantly have to deal with the needs of the population, to meet which have the resources, but their resources are limited, so the use of marketing priorities and strategies is particularly effective and provides massive 
Citation: Morozova GA (2015) Realization the Marketing Approach in the Management of the Region. Int J Econ and Manage Sci 4: 215. doi: 10.4172/2162-6359.1000215

Page 3 of 3

support power structures, increase their confidence in the policies and the active participation of the population in the implementation of development strategies. State civil servants and municipal employees as a result of these actions form the temptation of thinking that focuses on the needs of citizens.

Realization of the marketing management approach allows to form the structure of the economy of regions in line with the needs of society, provides a more efficient use of funds during the market reforms.

\section{References}

1. Morozova GA (2009) Competitiveness in today's monograph, Nizhniy Novgorod, IZD-vo VVAGS.

2. Morozova GA (2009) Marketing effort in the region. Monograph. Nizhniy Novgorod, VVAGS Publishing House.

3. Morozova GA (2010) Practical marketing technologies in the monograph. - Nizhniy Novgorod, IZD-vo VVAGS.

4. Morozova GA (2012) Sustainable development of the region in the monograph. - IZD-vo Russian Presidential Academy of National Economy and Public Administration. 